\title{
AVALIAÇÃO INSTITUCIONAL DA ESCOLA POLITÉCNICA DE PERNAMBUCO: O OLHAR DO ESTUDANTE DE ENGENHARIA SOBRE A PRÁTICA PEDAGÓGICA DOCENTE
}

DOI: 10.37702/2175-957X.COBENGE.2021.3524

Clarissa Perruci Farias - clarissaperruci@gmail.com

Escola Politécnica da Universidade de Pernambuco

Rua José Bonifácio 1141

50710-001 - Recife - PE

ANNA LÚCIA MIRANDA COSTA - annalucia@poli.br

UNIVERSIDADE DE PERNAMBUCO

RUA BENFICA 455

50720-001 - RECIFE - PE

Arthur Wanderley Ferreira Dos Santos - Arthur.aw109@gmail.com

Escola Politécnica da Universidade Pernambuco

Rua Poeta Zezito Neves 71

51020-200 - Recife - PE

Emilia Rahnemay Kohlman Rabbani - emilia.rabbani@upe.br

Universidade de Pernambuco

Rua Benfica 455

50720-001 - Recife - PE

Resumo: Este artigo versa sobre uma pesquisa vivenciada numa escola de Ensino Superior de Engenharia, em Pernambuco. Objetiva avaliar a prática pedagógica docente vivenciada durante o Período Letivo Suplementar (agosto-novembro de 2020), durante o qual tornaram-se necessárias mudanças significativa, como a transição do ensino presencial para o ensino remoto. Para a realização da ação denominada Avaliação da Prática Pedagógica Docente, a Comissão Setorial de Avaliação juntamente com Núcleo de Apoio Psicopedagógico Inclusivo (NAPSI) dedicaram-se a analisar 220 respostas obtidas através de um questionário online aplicado por meio da plataforma Google Forms. Foram identificados temas relacionados à metodologia das aulas; ao planejamento e organização dos encontros remotos; à coerência entre as práticas de avaliação da aprendizagem e 
os conteúdos apresentado; à familiaridade com o uso de ferramentas utilizadas; e à adaptação ao estilo de aulas remotas. A análise mostrou que tanto as ações relacionadas à prática docente quanto à adaptação dos discentes foram avaliadas de maneira positiva, dado expressado pela maioria dos respondentes satisfeitos com a metodologia desenvolvida durante o período. A partir dos resultados identificados é possível concluir que pesquisas de acompanhamento da prática pedagógica docente são necessárias quando compreendidas como oportunidade de investigar a qualidade da realidade avaliada, de forma que seja possível o redirecionamento da ação pedagógica em favor da aprendizagem efetiva do aluno.

Palavras-chave: Avaliação de estudantes, Período remoto, Prática docente, Investigação de qualidade 


\section{AVALIAÇÃO INSTITUCIONAL DA ESCOLA POLITÉCNICA DE PERNAMBUCO: O OLHAR DO ESTUDANTE DE ENGENHARIA SOBRE A PRÁTICA PEDAGÓGICA DOCENTE}

\section{INTRODUÇÃO}

A ação de avaliação pedagógica - seja da aprendizagem ou do ensino - é de suma relevância na Escola Politécnica de Pernambuco (POLI), instituição centenária com 109 anos de história e uma das 19 unidades de educação da Universidade de Pernambuco (UPE). Oferece cursos de graduação em engenharia (Computação, Mecânica, Controle e Automação, Civil, Eletrônica, Eletrotécnica e Telecomunicações) e um de Física de Materiais. Também oferta cursos de pós-graduação: mais de 20 cursos em nível de especialização, três mestrados e um doutorado. Sua comunidade escolar é constituída por aproximadamente 3.600 estudantes e 160 professores. É por esse portfólio acadêmico que a gestão prioriza ações que objetivam manter a qualidade e excelência na formação dos futuros profissionais através da implantação de estratégias avaliativas coerentes com seus princípios orientadores.

Dos debates internos à Instituição em torno deste tema emergem questões relevantes relacionadas à própria finalidade da prática avaliativa, como: a formação pedagógica do professor e a qualidade de sua prática pedagógica. Quanto à formação do professor, não se perde de vista que a natureza da formação acadêmica do professor de engenharia se caracteriza por bacharéis com pouco ou nenhum conhecimento sobre as especificidades que envolvem o desenvolvimento do processo de ensino-aprendizagem. $E$ quanto a sua prática pedagógica, se entende que há uma relação significativa entre esta ausência de conhecimentos pedagógicos mais aprofundados e a metodologia utilizada (COSTA, 2021). Ou seja, por pouco saber sobre o pedagógico, o professor de engenharia muitas vezes se utiliza de suas experiências estudantis para definir sua prática metodológica e, enquanto vivencia essa prática, constitui sua formação docente em serviço.

Por este contexto, toda e qualquer oportunidade de se avaliar a prática pedagógica docente na POLI se transforma em um indicador de possíveis mudanças em favor de sua melhorla (CUNHA, 2010; LUCKESI, 2011; SAUL, 2010). Esta certeza se concretiza há pouco mais de cinco anos, desde a implantação de uma ação denominada de Avaliação da Pratica Pedagógica Docente (COSTA et al, 2018; FERREIRA et. al., 2019; 2020), Coordenada pelo Núcleo de Apoio Psicopedagógico Inclusivo (NAPSI).Trata-se de uma ação já reconhecida pela comunidade acadêmica porque sua viabilização envolve professores e estudantes, transformando-a numa estratégia legitimada pelo protagonismo dos indivíduos envolvidos no ato educativo.

Antes de seguir com o intento de pontuar a última edição de uma destas oportunidades avaliativas, é importante ressaltar a definição do conceito de avaliação que norteia este trabalho. Em acordo com Luckesi (2011) se admite que a avaliação é compreendida como o ato de "(...) investigar a qualidade daquilo que constitui seu objeto de estudo e, por isso mesmo retrata sua qualidade" (p. 13). Tal definição é acompanhada pelo pressuposto que a avaliação se constitui como um elemento indissociável da prática pedagógica e que, de caráter contínuo, precisa assumir a finalidade de subsidiar a busca pela melhora da qualidade dos resultados, quer seja da aprendizagem ou ensino. Sua efetividade é amplamente garantida a partir do nível de envolvimento das pessoas 
protagonistas do ato educativo, estudantes e professores, sujeitos que por direito são legítimos integrantes deste ato.

A definição de avaliação apresentada por Luckesi (2011) se aproxima do conceito de avaliação de perspectiva formativa e emancipatória defendida por Saul (2010) e Albuquerque e Oliveira (2012). Por se constituir como um ato problematizador, a prática avaliativa promove a crítica à realidade institucional. Aqui, os integrantes do ato educativo protagonizam novas formas de fazer rompendo com antigos determinismos enquanto dão vozes às necessidades de aprendizagem individuais e coletivas. Por isso seu caráter formativo e emancipador.

Ainda para contribuir com as reflexões sobre a importância da prática avaliativa, Amaral (2008) enfatiza que é necessário não perder de vista que são os pressupostos teóricos e epistemológicos que dão sentido à prática, e não às ferramentas ou estratégias utilizadas. Ressalta que o propósito de um instrumento e a forma como ele é utilizado determinam seu papel nesse processo. Testes e provas - geralmente atribuídos a uma prática de classificação e exclusão - podem se tornar aliados dos professores quando são usados como diagnóstico de uma realidade a ser modificada.

Janela-Afonso (2009) amplia a discussão quando define a avaliação como dispositivo pedagógico e enfatiza sua condição de conformar democraticamente a representação multicultural que transforma a escola, precisamente a escola pública, por ser um espaço de pessoas com as mais diversas necessidades e expectativas. Com intenção formativa, a prática avaliativa será vivida neste espaço com pluralidade de técnicas e ferramentas, onde o diálogo é o eixo do processo. As pessoas envolvidas, sob uma ética responsável, identificam-se com os objetivos propostos e assumem seu papel em favor da melhora.

Para avaliar é necessário saber avaliar, declara García (2013). Esta afirmação resulta de sua compreensão de que o objetivo da avaliação é coletar um conjunto de informações relacionadas ao conhecimento prévio do aluno e seu contexto sociocultural. Essas informações devem ser utilizadas como ponto de partida nas organizações das atividades que atendam às necessidades individuais e coletivas do grupo. Um objetivo contrário a isso coloca a avaliação a serviço da educação que reconhece nos professores o papel de detentor de uma verdade inquestionada. O conhecimento assim transmitido não tem articulação com o cotidiano dos alunos, suas expectativas e seu contexto sociocultural. Essa prática resulta em um ato de examinar a aprendizagem e não avaliá-la (LUCKESI, 2011).

Após a reflexão em torno do entendimento do conceito de avaliação defendido, se parte para contextualização do tempo/espaço em que se desenvolveu esta pesquisa. É sabido que a situação pandêmica instalada no mundo em março de 2020 provocou o redirecionamento da ação educativa em todos os níveis e modalidades de ensino. Com a Universidade de Pernambuco não foi diferente. Sob as orientações da Resolução № 0058/2020 emitido pelo Conselho de Ensino, Pesquisa e Extensão (CEPE), os gestores das Unidades de Educação em conjunto com seus respectivos coordenadores de curso implantaram atividades de ensino não presencial em caráter excepcional através da viabilização de um Período Letivo Suplementar (PLS).

$\mathrm{Na} \mathrm{POLI}$, entre outras providências, foi planejado e desenvolvido um curso direcionado ao corpo docente sobre ferramentas virtuais. O reconhecimento referente a natureza da formação do professorado, aliado ao cuidado com sua prática pedagógica diante de uma situação diferente de todo que já havia sido vivenciado, justificaram a urgência em promover tal curso. Ainda que sob o efeito da surpresa diante do que se passava, fica aqui o registro do significativo trabalho coletivo que foi coordenado pela 
gestão da Instituição, assim como o reconhecido envolvimento do corpo docente nos inúmeros encontros de planejamento pedagógico.

Sem perder a sensibilidade no olhar sobre as ações postas em prática considerando o contexto em si, a Comissão Própria de Avaliação (CPA) da Universidade se preparou para ouvir sua comunidade acadêmica em novembro de 2020, no final do Período Letivo Suplementar (PLS). Seria de valiosa importância saber das impressões de cada um e cada uma sobre a qualidade do que havia sido vivenciado. Ainda sem perspectiva quanto ao futuro, os integrantes das Comissões Setoriais instaladas nas Unidades de Educação reforçaram a ação, provocando um maior envolvimento de docentes e discentes.

Partindo dos pressupostos apresentados, a coordenação da Comissão Setorial de Avaliação da POLI atuou junto à coordenação do Núcleo de Apoio Psicopedagógico Inclusivo (NAPSI) para viabilizar a quinta edição da ação denominada Avaliação da Prática Pedagógica Docente. Juntas, as duas coordenações se dispuseram a fazer um recorte nos dados obtidos pela ação coordenada pela CPA (Avaliação Institucional 2020)) para analisar os dados referentes à sua própria comunidade acadêmica, identificando e analisando as respostas dos estudantes com relação a prática pedagógica docente considerando o uso das ferramentas virtuais.

Com esta perspectiva, este artigo que versa sobre essa ação da avaliação da prática pedagógica docente, estabelece como objetivo o de avaliar a prática pedagógica docente no período denominado PLS, justificado pelo reconhecimento da Instituição de sua importância, considerando-a como oportunidade de investigar a qualidade do que foi proposto. As pessoas protagonistas da ação consideram que os resultados, além de retratarem essa realidade, devem subsidiar a construção de novas estratégias pedagógicas mais coerentes com as necessidades de aprendizagens do alunado.

\section{PROCEDIMENTO METODOLÓGICO}

A pesquisa coordenada pela Comissão Própria de Avaliação (CPA, 2016) realizada em novembro de 2020 caracterizou o público respondente em quatro categorias: discentes, egressos, docentes e técnicos, das 19 Unidades de Educação e Saúde da UPE distribuídas no Estado de Pernambuco. É uma pesquisa que se classifica como descritiva, uma vez que busca descrever as características de determinadas populações ou fenômenos (GIL, 2007), e quantitativa, pois tem por base a quantificação dos dados e busca medir opiniões e informações utilizando os recursos da estatística (KNECHTEL, 2014).

Para atender aos objetivos deste artigo as coordenações envolvidas foi feito um recorte dos resultados de toda a pesquisa coordenada pela CPA e identificadas as respostas emitidas por discentes dos 7 cursos de engenharia ofertados pela Escola Politécnica de Pernambuco (POLI) e o curso de Física dos Materiais (Tabela 1). Foram identificadas um total de 220 respostas. 
Tabela 1 - Distribuição dos alunos/respondentes por curso

\begin{tabular}{c|c|c}
\hline Curso & Frequência & Percentual do total \\
\hline Graduação em Eng. Civil & 67 & $30,45 \%$ \\
\hline Graduação em Eng. de Controle e Automação & 17 & $7,73 \%$ \\
\hline Graduação em Eng. da Computação & 40 & $18,18 \%$ \\
\hline Graduação em Eng. de Telecomunicações & 8 & $3,64 \%$ \\
\hline Graduação em Eng. Eletrônica & 13 & $5,91 \%$ \\
\hline Graduação em Eng. Eletrotécnica & 22 & $10,00 \%$ \\
\hline Graduação em Eng. Mecânica & 23 & $10,45 \%$ \\
\hline Graduação em Física de Materiais & 1 & $0,45 \%$ \\
\hline Pós-Graduação em Geral & 29 & $13,18 \%$ \\
\hline Total & 220 & $100,00 \%$ \\
\hline
\end{tabular}

Fonte: Elaboração dos autores (2021)

Como instrumento de coleta de dados foi utilizado um questionário online, elaborado coletivamente pelos representantes da CPA e aplicado por meio da plataforma Google Forms, pois, o uso de questionários é a garantia de precisão na verificação dos objetos de investigação (HAIR, 2005). Além disso, considerando o contexto atual, a utilização deste instrumento possibilitou maior rapidez e eficácia com relação ao acesso dos respondentes por todo o estado de Pernambuco.

Para tratamento e análise dos dados foi utilizado a plataforma Microsoft Office Excel e o uso de estatística focando na distribuição de frequência das respostas, que por definição, permite classificar os dados em classes e obter as quantidades e porcentagens de cada dado. Como apresentado na introdução, este artigo centra atenção sobre a opinião do estudante participante com relação a prática pedagógica docente desenvolvida durante o PLS. Para tanto, foi feito um recorte e selecionados 5 perguntas/respostas: metodologia das aulas; planejamento e organização das aulas; coerência nas práticas de avaliação da aprendizagem com os conteúdos apresentados; familiaridade do estudante com o uso das ferramentas utilizadas; e adaptação ao estilo das aulas remotas.

\section{RESULTADOS E DISCUSSÕES}

A metodologia ou estratégias pedagógicas utilizados no ensino remoto em função do contexto pandêmico devem focar no protagonismo dos alunos, favorecer a motivação e oportunizar momentos de troca como opiniões, questionamentos e por fim encorajá-los a investigar o ambiente que enriquece sua aprendizagem (SMOLARECK; LUIZ, 2020). Por outro lado, efetuar a adaptação e a criação de materiais didáticos em formato digital, em curto prazo, tem sido um desafio, pois nem todos os professores têm um manejo das tecnologias da informação e comunicação bom o suficiente para utilizar as ferramentas digitais de aprendizado (PALMEIRA, 2020)

É a partir dos pressupostos apresentados que se deve analisar a Figura 1, correspondente a avaliação dos discentes com relação às metodologias vivenciadas pelo docente no período remoto. É possível observar que $41,81 \%$ dos alunos caracterizam a metodologia utilizada nas aulas remotas de forma positiva ao avaliarem como ótimo ou bom. Ao analisar o somatório dos itens ruim e péssimo, 27,73\%, percebe-se uma equivalência com o item regular. Isso mostra, que as metodologias empregadas no período remoto foram, no mínimo, satisfatórias para a maioria dos estudantes, visto que apenas 
$27,73 \%$ avaliaram negativamente. Considerando que a formação pedagógica docente é uma das perspectivas abordadas neste artigo, este resultado é relevante quando analisado sobre o ponto de vista desta problemática.

Figura 1 - Avaliação das Metodologias Vivenciadas

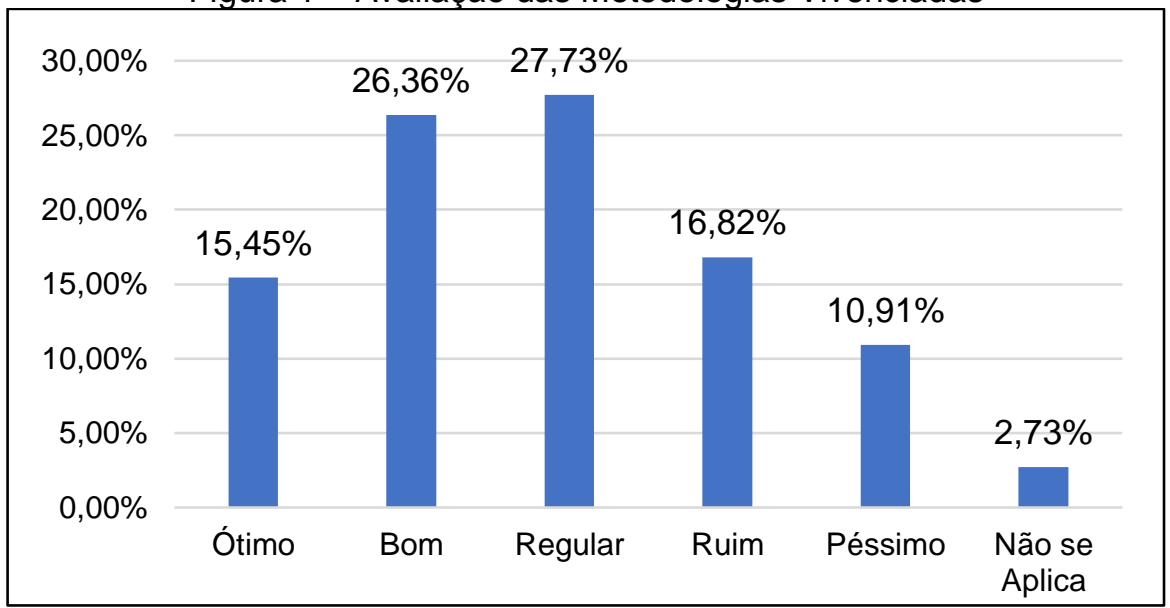

Fonte: Elaboração dos autores (2021)

Para Palmeira (2020), pelo fato das aulas de não serem presenciais, os encontros remotos devem ser planejados de forma cautelosa pelo docente, com a finalidade de valorizar a participação dos estudantes e viabilizar discussões e momentos em grupos, havendo a possibilidade de abrir diferentes grupos focais, de forma simultânea ou sequencial, para que ocorram as interações interpessoais. Este quesito exigiu do docente um estudo mais cuidadoso sobre o tema, no mínimo a realização de um planejamento coletivo onde a experiencia de um contribuiu como referência para seus pares.

Quanto ao planejamento e organização das aulas (Figura 2), constata-se que há a predominância do indicador bom com $28,18 \%$, apesar do quantitativo do item regular estar quase equiparado, com $27,73 \%$. Além disso, cerca de um quarto dos estudantes avaliam de maneira negativa a questão do planejamento e organização das aulas, mostrando que, por mais que seja uma primeira experiência de aula remota para a grande maioria, resultou de um bom planejamento.

Figura 2 - Planejamento e organização dos encontros remotos

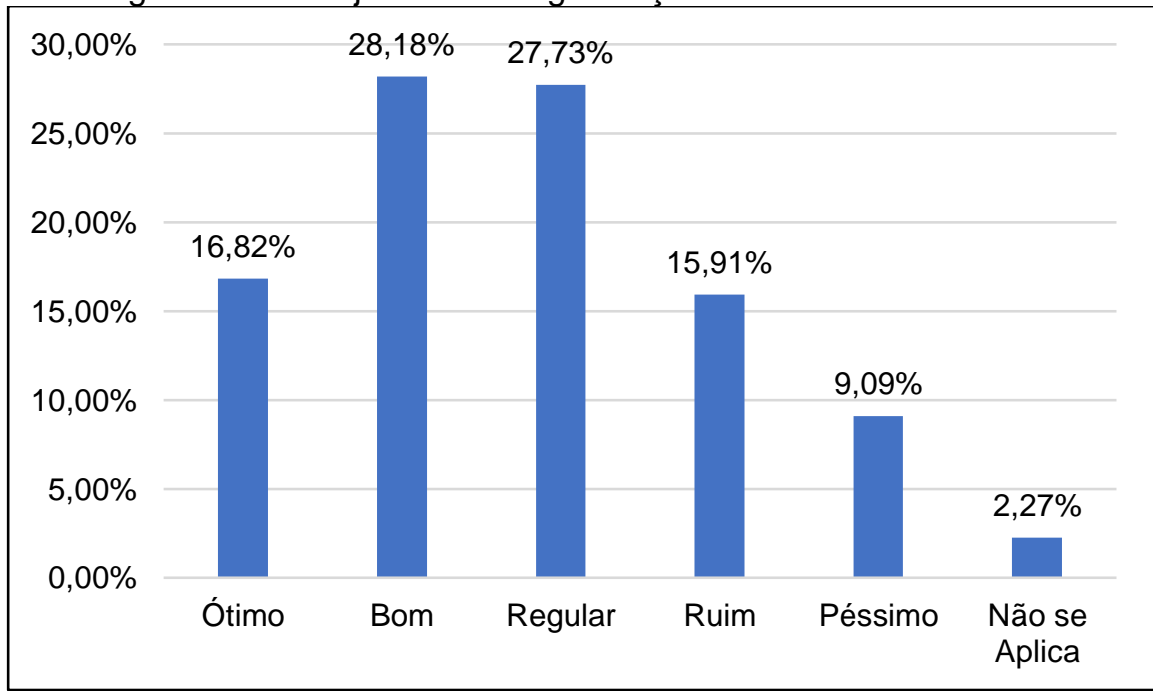

Fonte: Elaboração dos autores (2021) 
Com relação às práticas de avaliação de aprendizagem, o Parecer CNE/CP no $11 / 2020$ orienta que professores e redes de ensino tenham um olhar cuidadoso, flexível e que valorizem os esforços de cada aluno, no sentido de não ampliar a reprovação e a evasão escolar, mas de promover as aprendizagens essenciais que são possíveis para o momento. Ainda neste contexto, a coerência do que o professor ensina e a forma como ele avalia a aprendizagem são os primeiros fatores para encaminhar um bom processo educativo (MORETTO, 2007)

Sobre este tema, a Figura 3 revela que cerca da metade dos respondentes, 47,27\%, usaram os indicadores ótimo ou bom, sinalizando que por mais que exista a distância física entre os alunos e os professores e as mais diferentes formas de avaliar, ainda é possível manter a qualidade das avaliações.

Figura 3 - Coerência entre as práticas de avaliação da aprendizagem e os conteúdos apresentados

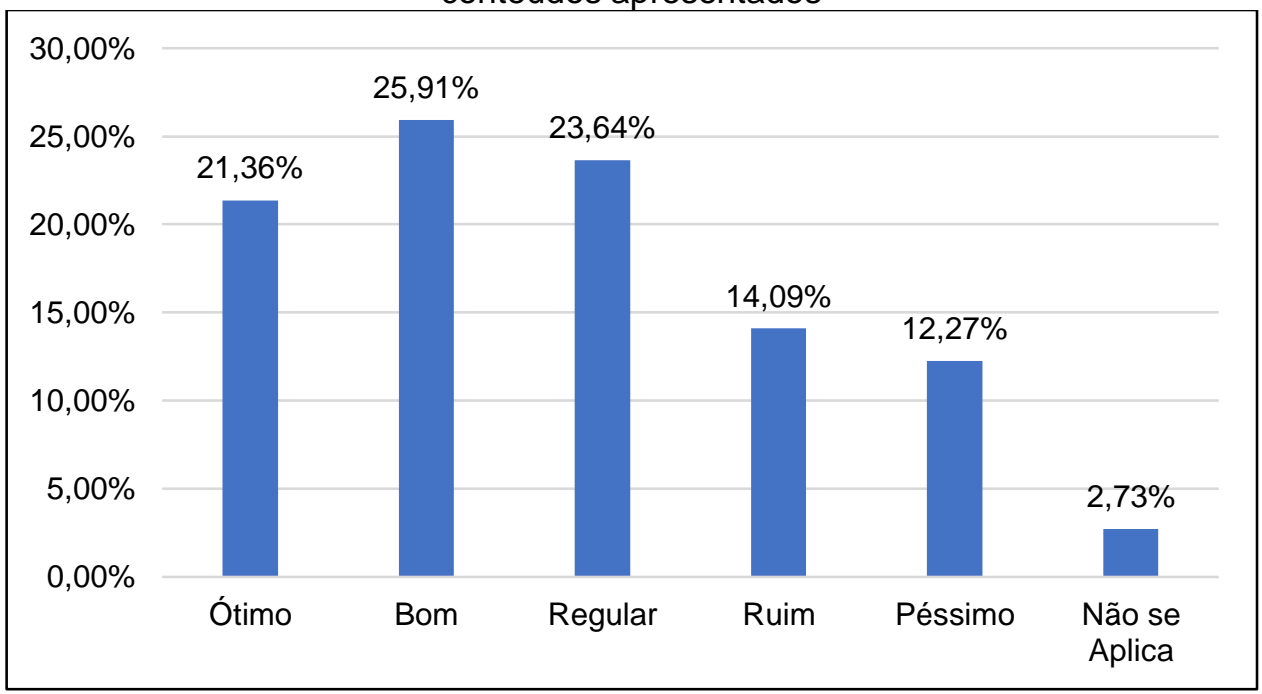

Fonte: Elaboração dos autores (2021)

Em meio ao cenário de pandemia, Dias e Pinto (2020) ressalta que grande parte das escolas e das universidades estão fazendo o possível para garantir o uso das ferramentas digitais, mas sem terem o tempo hábil para testá-las ou capacitar o corpo docente e técnicoadministrativo para utilizá-las corretamente. Como dito anteriormente, a POLI considerou a relevância em convidar o corpo docente para planejar coletivamente a proposta pedagógica a ser implantada, e entre as estratégias urgentes constava a de promover um curso para uso de ferramentas virtuais para o docente. No entanto, a ressalva é relevante pelo reconhecimento da necessidade de a coordenação pedagógica cuidar em promover sistematicamente espaços de formação continuada, de forma a consolidar o espaço enquanto estratégia de atendimento às necessidades de aprendizagens do aluno.

Os resultados obtidos a partir da análise da Figura 4 permitem afirmar que mais da metade dos respondentes estão familiarizados com o uso das ferramentas utilizadas, resultado revelado pela porcentagem dos indicadores ótimo e bom, 25,91\% e 37,27\%, respectivamente. Desta forma, destaca-se que o fato dos discentes estarem acostumados com os meios digitais utilizados sugere uma adaptação positiva do estudante, facilitando no momento de utilização dos recursos disponíveis, como por exemplo, o envio das atividades requeridas pelos docentes. 
Figura 4 - Familiaridade do estudante no uso das ferramentas utilizadas pelo docente

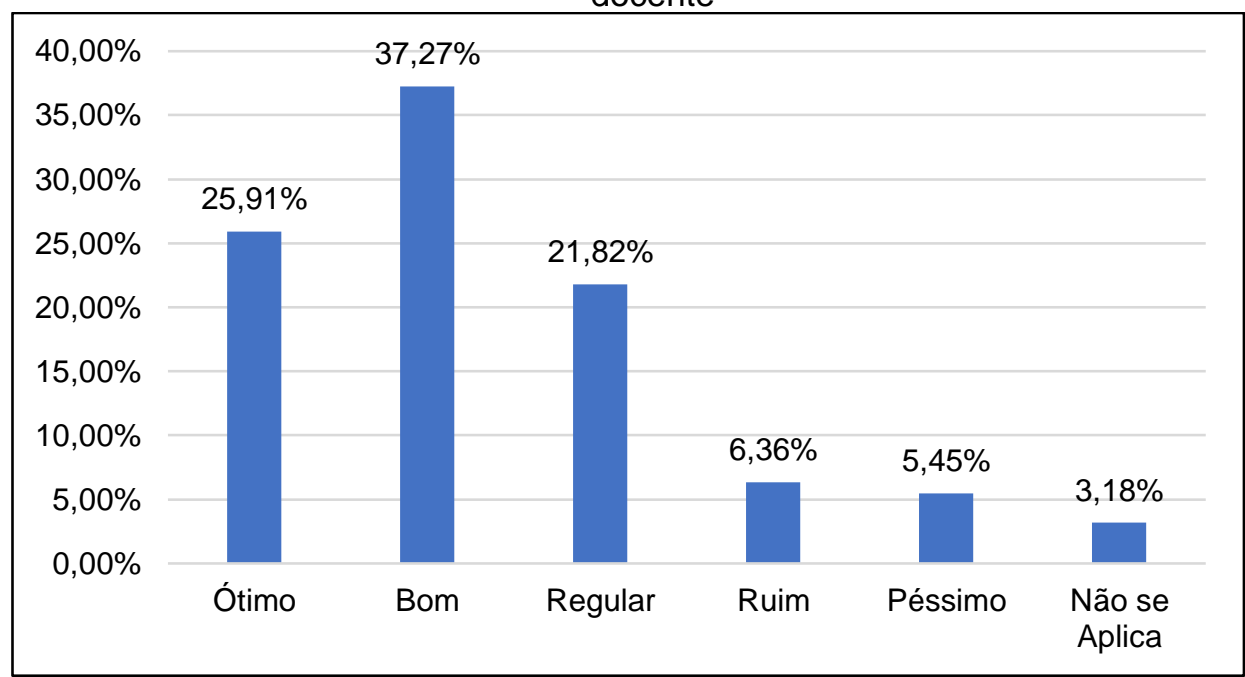

Fonte: Elaboração dos autores (2021)

No que diz respeito à adaptação dos discentes ao período remoto, a Figura 5 revela que aproximadamente $50 \%$ do alunado $(47,72 \%)$ considera a adaptação à forma de ensino remota de maneira positiva. Em contrapartida, cerca de um quarto $(26,37 \%)$ considera de maneira negativa. Essa adaptação pode ser influência, como visto nos resultados anteriores, da combinação dos pontos abordados na presente pesquisa, como a satisfação com as metodologias adotadas pelos docentes, o planejamento e organização das aulas e, principalmente, familiaridade com o uso das ferramentas adotadas, contribuindo para manutenção da qualidade de ensino.

Figura 5 - Adaptação ao estilo de aulas remotas

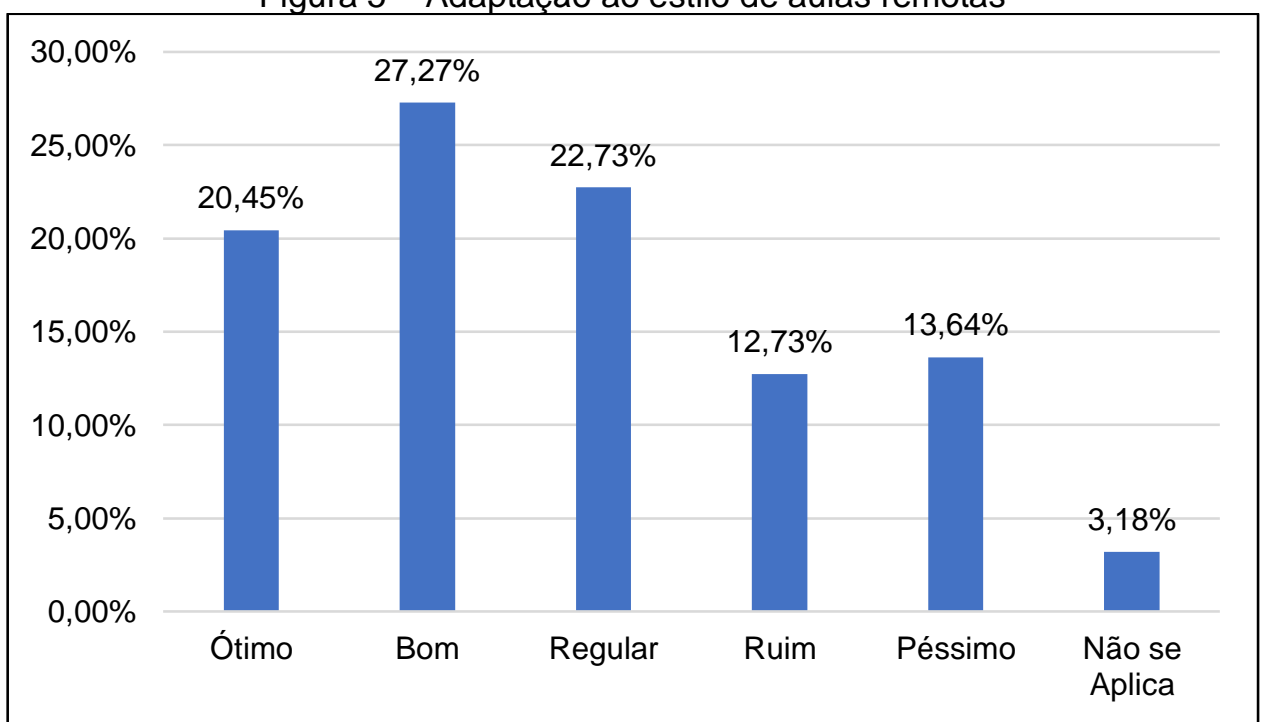

Fonte: Elaboração dos autores (2021) 


\section{CONSIDERAÇÕES FINAIS}

A relevância deste trabalho pode ser avaliada sob duas perspectivas: como resultante de um pensar coletivo que reconhece toda e qualquer oportunidade avaliativa como um elemento indissociável do ato educativo; e como oportunidade de consolidar um espaço criado (CSA, 2016) com a implantação da ação da Avaliação da Prática Pedagógica Docente. Num esforço coletivo, o tema da avaliação segue como ponto de pauta nos encontros junto aos coordenadores de curso, docentes e alunos. Os conceitos difundidos pelos estudiosos citados na Introdução subsidiam estes encontros que precisam ainda ser reconhecidos como espaços legítimos de formação continuada do professorado. É possível afirmar que muito se avançou neste sentido, mas os resultados de desempenho acadêmico do aluno da POLI revelam que ainda temos muito que fazer.

A pesquisa é relevante quando pensada como ferramenta indicativa de transformação de uma determinada realidade. Ao buscar compreender a percepção dos alunos acerca do período remoto de pandemia, favoreceu a produção de novas perspectivas de ação pedagógica. Mostrou-se como um instrumento valioso de entendimento sobre como está o aluno em meio ao processo de aprendizagem, possibilitando a identificação dos acertos e entendimento das possíveis falhas, pois que para a maioria das pessoas esta modalidade de ensino acontecendo pela primeira vez.

Ao analisar os resultados relacionados as ações que dizem respeito às práticas pedagógica docente - metodologia; planejamento e organização das aulas; e coerência nas práticas de avaliação da aprendizagem com os conteúdos apresentados -, identificamos resposta satisfatória por parte da maioria dos respondentes. Um dado relevante que foi tomado como uma constatação de todo o esforço empreendido pelo professorado. Ao tomar este resultado como ponto de pauta durante um encontro junto aos coordenadores, a gestão da POLI reconheceu o esforço de todos e validou a ação avaliativa como sugerem Albuquerque e Oliveira (2012) e Luckesi (2011): uma oportunidade de investigar a qualidade da realidade, protagonizada por seus autores. Esta perspectiva implica na identificação e compreensão dos erros como possibilidades de acertos.

A resposta do alunado no que diz respeito a sua familiaridade com o uso das ferramentas e adaptação ao estilo de aulas remotas, também sugere concordância e satisfação com o processo desenvolvido. Para responder aos questionamentos o alunado precisou assumir seu lugar enquanto protagonista de seu processo formativo e autoavaliarse. Este processo, de acordo com o que sugere Cunha (2010), rompe com paradigmas conservadores que relegam ao professor o direito único de avaliar o processo de ensino e aprendizagem e chama atenção do aluno para sua responsabilidade.

Os resultados obtidos com a pesquisa nos levaram a concluir que diante da necessidade de adaptação dos processos de ensino e aprendizagem ao chamado PLS, o corpo docente da POLI desenvolveu um bom trabalho, disponibilizando plataformas acessíveis e um adequado planejamento pedagógico. As atividades avaliativas propostas, coerentes com os conteúdos vivenciados, são indícios de que a prática avaliativa da Escola caminha para se tornar uma ação protagonizada pelos indivíduos envolvidos no ato educativo, conforme nos sugere Luckesi (2011).

Enfim, concluímos que a pesquisa em tela sugere a necessidade de desenvolver estudos futuros a partir da viabilização de novas edições da ação do Projeto de Avaliação da Prática Pedagógica Docente, mantendo seus objetivos: caracterizar as práticas pedagógicas vivenciadas na POLI e subsidiar a criação de estratégias pedagógicas favorecedoras do efetivo ensino e aprendizagem de qualidade. 


\section{Agradecimentos}

Gratidão aos discentes da Escola Politécnica de Pernambuco que se mostraram disponíveis para responder ao questionário ajudando a desenvolver este Projeto e à toda equipe atuante que colaborou para que ele pudesse ser realizado. Agradecemos também, ao diretor José Roberto Cavalcanti pelo apoio e incentivo e, especialmente aos que integram o Núcleo de Apoio Psicopedagógico Inclusivo (NAPSI).

\section{REFERÊNCIAS}

ALBUQUERQUE, T. de Souza., OLIVEIRA, E. da Silva. Avaliação da Educação e da Aprendizagem. Curitiba: IESDE Brasil S.A., 2012

AMARAL, M. C. Julgar, medir, diagnosticar, formar... afinal, para que serve a avaliação?. Mal-Estar e Sociedade, v.1, n.1, p.129-145, 2008.

\section{CSA-COMISSÃO SETORIAL DE AVALIAÇÃO DA POLI. Avaliação da Prática}

Pedagógica Docente. Projeto apresentado ao Conselho de Gestão Acadêmica e Administrativa da POLI/UPE. Recife, 2016.

COSTA, A.L.M. La evaluación formativa y emancipadora en la cultura docente del profesorado universitario. Un proceso de innovación evaluativa a través de la investigación-acción en la Escuela Politécnica de Pernambuco (Brasil). 2021. Tese (Doutorado) - Curso de Psicodidáctica: Psicología de la Educación y Didácticas Específicas. Universidad del País Vasco, Leioa, 2021. Disponível em: https://addi.ehu.es/handle/10810/50846 Acesso em: 06 mai.2021

COSTA, A. L. M. et. al. Avaliação da Prática Pedagógica Docente na Escola Politécnica da Universidade de Pernambuco. In: XLVI Congresso Brasileiro de Educação em Engenharia, 2018, Salvador. Anais. Salvador. Disponível em:

http://www.abenge.org.br/sis artigo doi.php?e=COBENGE\&a=18\&c=1569 . Acesso em 05 mai.2021.

Cunha, M.I. (2010). A docência como ação complexa. In M.I. da Cunha (ed.) Trajetórias e lugares de formação da docência universitária: da perspectiva individual ao espaço (pp. 19-34). Brasília. Junqueira \& Martins

DIAS, E.; PINTO, F. C. F. A Educação e a Covid-19. Ensaio: aval.pol.públ.Educ., Rio de Janeiro, v. 28, n. 108, p. 545-554, Set. 2020.

FERREIRA, A. L. M. et. al. Avaliação da Prática Pedagógica Docente na Escola Politécnica da Universidade de Pernambuco. In: XLVII Congresso Brasileiro de Educação em Engenharia, 2019, Fortaleza. Anais. Fortaleza. Disponível em: http://www.abenge.org.br/sis artigos.php . Acesso em 05 mai.2021 
FERREIRA, A. L. M. et. al. Avaliação da Prática Pedagógica Docente na Escola Politécnica da Universidade de Pernambuco. In: XLVIII Congresso Brasileiro de Educação em Engenharia, 2020. Anais. Disponível em: $\underline{\mathrm{h}}$ http://www.abenge.org.br/sis artigos.php . Acesso em 05 mai.2021

GARCIA, R. P. M. Avaliação da aprendizagem na educação a distância na perspectiva comunicacional. Editora UFRB, 2013.

GIL, A. C. Como elaborar projetos de pesquisa. 4. ed. São Paulo: Atlas, 2007

HAIR, J. et al. Fundamentos de métodos de pesquisa em administração. Bookman Companhia Ed, 2005.

JANELA-AFONSO, A. J. Avaliação educacional. Regulação e emancipação. São Paulo: Cortez, 2009

KNECHTEL, M. do R. Metodologia da pesquisa em educação: uma abordagem teóricoprática dialogada. Curitiba: Intersaberes, 2014.

LUCKESI, C.C. Avaliação da Aprendizagem componente do ato pedagógico. São Paulo: Cortez, 2011.

MORETTO, V. P. Prova: Um momento privilegiado de estudo, não um acerto de contas. Rio de Janeiro: Editora, Lamparina: 7a ed., 2007.

PALMEIRA, R. L. et. al. As metodologias ativas de ensino e aprendizagem em tempos de pandemia: a utilização dos recursos tecnológicos na Educação Superior. HOLOS, v. 5, p. 1-13, nov. 2020.

SAUL, A. M. Avaliação Emancipatória. Desafio à teoria e a prática de avaliação e reformulação de currículo. São Paulo: Cortez, 2010

SMOLARECK, R. D. LUIZ, R. S. Metodologias ativas, reflexões para reinventar o ensino de geografia, em época de pandemia. eduCAPES, 14 mai. 2020. Disponível em: https://educapes.capes.gov.br/handle/capes/569403. Acesso em: 21 abr. 2020.

\title{
INSTITUTIONAL ASSESSMENT OF THE ESCOLA POLITÉCNICA DE PERNAMBUCO: THE ENGINEERING STUDENT'S VIEW ON THE PEDAGOGICAL TEACHING PRACTICE
}

\begin{abstract}
This article deals with a research carried out in a Higher Education School of Engineering, in Pernambuco. It aims to assess the teaching pedagogical practice experienced during the Supplementary Academic Period (august to November of 2020), which significant changes became necessary, such as the transition from face-to-face to remote education. For carrying out the action called Assessment of Teaching Pedagogical Practice, the Comissão Setorial de Avaliação (CPA) together with the Núcleo de Apoio Psicopedagógico Inclusivo (NAPSI) were dedicated to analyze 220 responses obtained through an online questionnaire applied through the Google Forms platform. Were identified
\end{abstract}


issues related to the the methodology of the classes; the planning and organization of the remote meetings; the consistency between the learning assessment practices and the content presented; the familiarity with the tools used; and the adaptation to the remote classroom style. The analysis showed that both the actions related to teaching practice and the adaptation of the students were positively assessed, a fact expressed by the majority of the respondents who were satisfied with the methodology developed during the period. From the results, it is possible to conclude that research to follow up the teaching practice is necessary when it is understood as an opportunity to investigate the quality of the reality being assessed, so that it is possible to redirect the pedagogical action in favor of effective student learning.

Keywords: Student's Assessment, Remote period, Teaching practice, Quality research. 